\title{
Carbapenem resistant Enterobacteriaceae neonatal gut colonization: A future concern in healthcare settings
}

\author{
Debapriya Das Choudhury ${ }^{1, *}$, N P Singh ${ }^{2}$, Sumit Rai ${ }^{3}$, Prerna Batra ${ }^{4}$, Vikas Manchanda ${ }^{5}$ \\ ${ }^{\mathbf{1}}$ Assistant Professor, Dept. of Microbiology, D.Y. Patil Medial College, Navi Mumbai, Maharashtra, ${ }^{2}$ Professor and HOD, Dept. \\ of Microbiology, University College of Medical Sciences \& GTB Hospital, New Delhi, ${ }^{3}$ Associate Professor, Dept. of \\ Microbiology, Super Speciality Paediatric Hospital \& PG Teaching Institute, Noida, Uttar Pradesh, ${ }^{4}$ Associate Professor, Dept. of \\ Paediatrics, University College of Medical Sciences \& GTB Hospital, New Delhi, ${ }^{5}$ Associate Professor, Maulana Azad Medical \\ College, Delhi, India
}

*Corresponding Author:

Email: debapriya.dmr@gmail.com

Received: $21^{\text {st }}$ February, 2018

Accepted: $21^{\text {st }}$ May, 2018

\begin{abstract}
Introduction: Carbapenem-resistant Enterobacteriaceae (CRE) isolates are resistant to carbapenem and other beta-lactam drugs. Infections with these CREs have been reported in different age groups and are difficult to treat because of their resistant pattern and thus, they have become epidemiologically important.

Materials and Methods: Rectal swabs from 150 term/ late preterm neonates (> 35 weeks) and 150 preterm neonates (<35 weeks) were collected who were hospital delivered and admitted in NICU and likely to stay $>3$ days. Three rectal swabs were taken; $1^{\text {st }}$ within $24 \mathrm{hrs}$ of birth (day 0), $2^{\text {nd }}$ on day 3 and $3^{\text {rd }}$ before discharge (day 4-10). They were screened for CRE in stool/rectal swab according to CDC criteria. These were further confirmed by following CLSI guidelines (MHT) to observe the carbapenemases production and real-time PCR for bla $\mathrm{NDM}_{\mathrm{N}-1}$, bla $\mathrm{IMP}$, blaviM, bla $\mathrm{KPC}_{\mathrm{NP}}$

Results: A total of $8.7 \%$ (26/300) possible CREs were isolated in term/late preterm $(15 / 26,57.7 \%)$ and preterm neonates (11/26, $42.3 \%$ ). Klebsiella pneumoniae was the commonest organism. In total, 22/26 (84.6\%) possible CREs were MHT positive and rest 4 were MHT negative. The majority of MHT positive CREs were multidrug-resistant whereas MHT negative CREs was sensitive to tested carbapenem drugs. Carbapenemases genes (bla $\mathrm{NDM}_{-1=10}$, blaviM=8, bla $a_{\mathrm{IMP}=1}$, bla $_{\mathrm{KPC}=0}$ ) were identified in 19/26 of possible CREs, but multiple carbapenemases genes were not found.

Conclusions: In this study, neonates were colonized with CRE within their gut as early as 72 hours after birth. This can cause infection in the postnatal period and may lead to spread of CRE in the community.
\end{abstract}

Keywords: Carbapenem-Resistant Enterobacteriaceae, Neonatal Intensive care Unit, Modified Hodge Test.

\section{Introduction}

Carbapenems are potent beta-lactam antibiotics having broad-spectrum activity and thus, have been traditionally rendered as 'last resort' antibiotics. They are active against many aerobic and anaerobic grampositive and gram-negative organisms including Enterobacteriaceae. ${ }^{1}$

Inappropriate empirical antibiotic therapy is independently associated with poorer outcomes in patients with bacteremia due to Enterobacteriaceae. ${ }^{2}$ The emergence and spread of extended-spectrum betalactamases (ESBL) and plasmid-mediated AmpC producing Enterobacteriaceae has led to use of carbapenems as frontline empirical antibiotics in many more clinical situations than before. Until recently, carbapenems were mostly used in the treatment of serious bacterial infection eg. post-operative wound infections and in intensive care units (ICU) settings. Now with the emergence of transferable resistance among the carbapenem-resistant Enterobacteriaceae (CRE) isolates which render them non-susceptible to all beta-lactam antibiotics, a public health emergency situation has arisen, as very limited available antimicrobials show activity against these isolates. ${ }^{1}$
The first carbapenemases producer in Enterobacteriaceae was identified in $1993 .{ }^{3}$ Since then, a large variety of carbapenemases has been identified in Enterobacteriaceae. In developed countries like the United States, carbapenem-resistant Klebsiella pneumoniae strains harbor the Klebsiella pneumoniae carbapenemases (KPC's). There are also reports of the presence of carbapenemases in organisms other than Enterobacteriaceae like Acinetobacter baumannii, Pseudomonas aeruginosa around the globe.,

In developing countries like India, the epidemiological status of carriage of CRE is still unknown. There are reports of CREs in India isolated from blood, pus, stool and other body fluids from adults as well as children. ${ }^{5-7}$ But till now, studies have not been conducted among neonates who are institutionally delivered and admitted in neonatal intensive care unit (NICU), to find out their gut colonization, as they can act as a potential source of transmission of such isolates in the community. Thus, keeping this fact as front-runner, the present study was conducted to find out the colonization of CRE in the naive gut of neonates who were institutionally delivered and admitted in NICU of our hospital. 


\section{Materials and Methods}

The study was conducted in the Department of Microbiology and the samples were collected from Department of Paediatrics of the same tertiary care hospital, East Delhi for over a period of one year and approved by the institutional Ethical committee.

A total of 150 term/late preterm ( $>35$ weeks) and 150 preterm $(<35$ weeks) hospital delivered neonates who were admitted in NICU and likely to stay for $>3$ days were included in the study after taking written consent from the parents. Since no studies have been conducted to best of our knowledge, there is no prevalence value available to calculate the sample size in our study. However, this was a pilot study and thus, it was decided to take $10 \%$ of the total admission in NICU. The data collected from NICU shows that a total number of neonates staying for more than three days is approximately 1500 in each group over the year. Hence, 150 neonates in each study group were considered as sample size.

Random samples were collected twice weekly to achieve the sample size. The rectal swabs (sterile cotton swab) from neonates were taken on day 0 (within $24 \mathrm{hrs}$ of birth), day 3 (on $3^{\text {rd }}$ day birth) and before discharge (day 4 - day 10) and were processed within 15 - 20 minutes of collection of the samples according to centre for disease control (CDC) criteria of detection of carbapenem-resistant or carbapenemase-producing, Klebsiella sp. and E. coli from rectal swabs. ${ }^{8}$ Briefly, rectal swabs were put in trypticase soy broth containing ertapenem disc $(10 \mu \mathrm{g})$ and incubated overnight at $37^{\circ} \mathrm{C}$ and on the next day, subcultured on Mac-Conkey agar plate and looked for lactose fermenting colonies, which were identified to species level. ${ }^{9}$ Modified Hodge Test (MHT) was performed on these possible CRE isolates. ${ }^{10}$ Antibiotic Susceptibility Testing: The antibiotic susceptibility of all the Enterobacteriaceae isolates was determined by disc diffusion (Kirby-Bauer) method for the following antibiotics: amikacin $(30 \mu \mathrm{g})$, ampicillinsulbactam $(10 / 10 \mu \mathrm{g})$, ciprofloxacin $(5 \mu \mathrm{g})$, colistin $(10$ $\mu \mathrm{g})$, ertapenem $(10 \mu \mathrm{g})$, imipenem $(10 \mu \mathrm{g})$, meropenem $(10 \mu \mathrm{g})$, cefotaxime $(30 \mu \mathrm{g})$, gentamicin $(10 \mu \mathrm{g})$, netilmicin $(30 \mu \mathrm{g})$, piperacillin/tazobactam $(100 / 10)$ polymixin B (300 units), tigecycline $(15 \mu \mathrm{g}) .{ }^{10}$ For epidemiologic purposes, microorganisms predominantly bacteria, that are resistant to one or more classes of antimicrobial agents are labeled as a multidrug-resistant organism (MDR). ${ }^{11}$

Modified Hodge Test: CLSI guidelines for MHT were followed. ${ }^{10}$ Briefly, E. coli ATCC 25922 suspension corresponding to $0.5 \mathrm{McF}$ arland dilutions was further diluted 1:10 using normal saline. This was used to make the lawn culture on Muller Hinton agar plate and allowed to dry for 3-5 minutes. An ertapenem disc $(10 \mu \mathrm{g})$ was placed in the center of the plate and the test organisms were streaked at the right angle from the edge of the disc to edge of the plate along with positive control (wild strains of the previous study) and negative control ( $E$. coli ATCC 25922). On one plate, four organisms were tested and plates were incubated at $35^{\circ} \mathrm{C} \pm 2{ }^{\circ} \mathrm{C}$ in ambient air for $16-24$ hours and clover leaf-type indentation within the zone of inhibition of $E$. coli at the intersection of the test organism was observed.

Real-Time Polymerase Chain Reaction (RT-PCR): DNA was extracted from CRE isolates using 'HiPura ${ }^{\mathrm{TM}}$ Bacterial Genomic DNA Extraction Kit' (Himedia, India) The DNA was subjected to Real-time PCR for $b l a_{\mathrm{NDM}-1}, b l a_{\mathrm{VIM}}, b l a_{\mathrm{IMP}}, b l a_{\mathrm{KPC}}$ using SYBER green chemistry. Briefly, $20 \mu$ lof the reaction mixture which consisted of $5 \mu \mathrm{l}$ extracted DNA, $1 \mu \mathrm{l}$ of forward and reverse primer (Genex Life Science, India) each (conc. $10 \mathrm{pmol} / \mu \mathrm{l}), 10 \mu \mathrm{l}$ Lightcycler DNA master mix SYBER green-I (Roche) and $3 \mu 1$ nuclease free water in one well of 96 well reaction plate was used. The reaction plate was loaded and real-time PCR was performed along with respective positive and negative controls on Roche light cycler 480 (Roche Applied Sciences, India) and the results were studied by $T_{m}$ calling. In the case of SYBER green I DNA binding dye, the melting temperature for or $\mathrm{T}_{\mathrm{m}}$ is defined as the point at which half of the DNA is double-stranded and half is single-stranded. The resultant amplicons were electrophoresed on $2 \%$ agarose gel.

RT-PCR Conditions: NDM-1: The primers and PCR cycles for NDM-1 were performed as per the protocol by Manchanda et al. ${ }^{12}$

VIM: The primers were used from Mandes et $\mathrm{al}^{13}$ and PCR cycles used in the present study for VIM were standardized as follows: Initial denaturation at $95^{\circ} \mathrm{C}$ for 10 mins $\Sigma 1$ cycle, amplification 45 cycles of $95^{\circ} \mathrm{C}$ for 10 second(s), $60{ }^{\circ} \mathrm{C}$ for the $30 \mathrm{~s}$ and $72{ }^{\circ} \mathrm{C}$ for $20 \mathrm{~s}$, melting step 1 cycle of $95^{\circ} \mathrm{C}$ for $5 \mathrm{~s}$, and $65^{\circ} \mathrm{C}$ for $1 \mathrm{~min}$, cooling at $40{ }^{\circ} \mathrm{C}$ for $10 \mathrm{~s}$.

IMP: The primers were used according to Mandes et $\mathrm{al}^{13}$ and PCR cycles used in the present study for IMP were standardized as follows: initial denaturation at $95^{\circ} \mathrm{C}$ for 10 mins $\Sigma 1$ cycle, amplification 45 cycles of $95^{\circ} \mathrm{C}$ for $10 \mathrm{~s}, 58^{\circ} \mathrm{C}$ for $45 \mathrm{~s}$ and $72{ }^{\circ} \mathrm{C}$ for the $30 \mathrm{~s}$, melting step 1 cycle at $95{ }^{\circ} \mathrm{C}$ for $5 \mathrm{~s}$ and, $65^{\circ} \mathrm{C} 1 \mathrm{~min}$, cooling at $40{ }^{\circ} \mathrm{C}$ for $10 \mathrm{~s}$.

KPC: The primers were used according to Wang $\mathrm{L}$ et $\mathrm{al}^{14}$ and PCR cycles used in our study for were standardized as follows initial denaturation at $95{ }^{\circ} \mathrm{C}$ for 10 mins $\Sigma 1$ cycle, amplification at 45 cycles of $95^{\circ} \mathrm{C}$ for $10 \mathrm{~s}, 60^{\circ} \mathrm{C}$ for $30 \mathrm{~s}$ and $72{ }^{\circ} \mathrm{C} 10 \mathrm{~s}$, melting 1 cycle at $95{ }^{\circ} \mathrm{C}$ for $5 \mathrm{~s}$ and $65{ }^{\circ} \mathrm{C}$ for $1 \mathrm{~min}$, cooling at $40{ }^{\circ} \mathrm{C}$ for $10 \mathrm{~s}$.

\section{Results}

Out of 300 neonates studied, 26 (8.7\%) had possible CRE according to CDC criteria for detection of CRE in stool/rectal swab. No possible CRE were isolated on day 0 of admission. Six out of $26(23.08 \%)$ of possible CRE isolates were obtained on day 3 of admission and 20 $(76.92 \%)$ at the time of discharge (day $4-10$ ) the antibiogram of the 6 neonates colonized on day 3 
remained the same at the time of their discharge. (Table 2).

Klebsiella pneumoniae $(18 / 26,69.2 \%)$ was the commonest organism among the possible CREs followed by Citrobacter spp. (4/26, 15.3\%), Enterobacter spp. $(2 / 26,7.6 \%)$ and Escherichia coli (2/26, 7.6\%). Eleven (11) and seven (7) Klebsiella pneumoniae were isolated in term/late preterm and preterm neonates, respectively and 2 Citrobacter spp. each in both the groups. Two (2) Enterobacter spp. were isolated in term/late preterm neonates and 2 Escherichia coli in preterm neonates only (Fig. 1).

Twenty-two of the 26 possible CREs were MHT positive, 18 being resistant and 4 sensitive to all three tested carbapenem drugs. Out of 26 possible CREs, 25 were MDR showing five different drug resistance patterns, while 1 strain was sensitive to all the tested antimicrobials (Table 3).

Real Time-PCR: Carbapenemases genes were identified in 19 possible CREs by Real-Time PCR ( bla $_{\mathrm{NDM}-1=10}$, bla $_{\mathrm{VIM}=8}$, bla $_{\mathrm{IMP}=1}$, bla $\left.a_{\mathrm{KPC}=0}\right)$. (Fig. 2-5)

More than one gene was not found in any isolates. 18 of these were resistant to carbapenem drugs and MHT positive. One isolate which harbored the carbapenemases gene was sensitive to the tested carbapenem drugs, but MHT positive. (Table 4)

Table 1: Primers

\begin{tabular}{|c|c|c|}
\hline Primer & Sequence & Amplicon size (bp) \\
\hline NDM-1F & 5`GCTGGCGGTGGTGACTC-3` & \multirow{2}{*}{106} \\
\hline NDM-1R & 5-GGCAAGCTGGTTCGACAAC-3` & \\
\hline VIM-F & 5`-GTTTGGTCGCATATCGCAAC-3` & \multirow{2}{*}{382} \\
\hline VIM-R & 5-AATGCGCAGCACCAGGATAG-3` & \\
\hline IMP-F & 5'GAATAGGGTGGCTTAATTCTC-3` & \multirow{2}{*}{188} \\
\hline IMP-R & 5`CCAAACCACTACGTTATC-3` & \\
\hline KPC-F & 5`TTGTTGATTGGCTAAAGGG-3` & \multirow{2}{*}{106} \\
\hline KPC-R & 5`CCATACACTCCGCAGGTT-3` & \\
\hline
\end{tabular}

Table 2: Prevalence of possible CRE using CDC criteria

\begin{tabular}{|l|c|c|c|c|}
\hline \multirow{2}{*}{ Neonates } & \multicolumn{3}{|c|}{ Rectal Swabs } & \multirow{2}{*}{$\begin{array}{c}\text { Total no. of neonates with } \\
\text { possible CRE }\end{array}$} \\
\cline { 2 - 4 } & Day 0 n(\%) & Day 3 n(\%) & Day 4-10 n(\%) & $15(10 \%)$ \\
\hline Term/late preterm (150) & $0(0 \%)$ & $3(2 \%)$ & $12(8 \%)$ & $11(7.3 \%)$ \\
\hline Preterm (150) & $0(0 \%)$ & $3(2 \%)$ & $8(5.3 \%)$ & $26(8.7 \%)$ \\
\hline Total (300) & $0(0 \%)$ & $6(2 \%)$ & $20(6.6 \%)$ & \\
\hline
\end{tabular}

Table 3: Drug resistance patterns in CRE

\begin{tabular}{|l|c|c|}
\hline \multicolumn{1}{|c|}{ Drug Resistance } & No. of organisms $(\mathbf{n = 2 6})$ & Resistant to drugs \# \\
\hline Pattern 1 & 15 & AK, A/S, CIP, CTX, PIT, GEN, NET, MEM ETP, IPM \\
\hline Pattern 2 & 4 & A/S, CIP, CTX, PIT, GEN \\
\hline Pattern 3 & 3 & AK, A/S, CIP, CTX, PIT GEN, NET \\
\hline Pattern 4 & 2 & AK, A/S, CIP, CTX, PIT, NET, MEM, ETP, IPM \\
\hline Pattern 5 & 1 & A/S, CTX, PIT, GEN, MEM, ETP, IPM \\
\hline Pattern 6 & 1 & Sensitive to all drugs \\
\hline
\end{tabular}

\# AK=Amikacin, A/S=Ampicillin-Salbactam CIP=Ciprofloxacin, CTX=Cefotaxime, PIT=Pipercillin-Tazobactam, GEN=Gentamicin, NET=Netilmicin, MEM=Meropenem, ETP=Ertapenem, IMP=Imipenem

Table 4: Carbapenemases genes in possible CREs

\begin{tabular}{|c|c|c|c|c|c|c|c|c|c|}
\hline \multirow[t]{2}{*}{$(n=26)$} & \multicolumn{2}{|c|}{ bla NDM-1 } & \multicolumn{2}{|c|}{ blavIM } & \multicolumn{2}{|c|}{ bla IMP } & \multicolumn{2}{|c|}{ bla $_{\mathrm{KPC}}$} & \multirow{2}{*}{$\begin{array}{l}\text { No. of isolates harbouring } \\
\text { carbapenemases genes }\end{array}$} \\
\hline & + & - & + & - & + & - & + & - & \\
\hline $\begin{array}{l}\text { MHT positive } \\
\text { C Sensitive }(n=4)\end{array}$ & 1 & 3 & 0 & 4 & 0 & 4 & 0 & 4 & 1 \\
\hline $\begin{array}{l}\text { MHT positive } \\
\text { C Resistant }(n=18)\end{array}$ & 9 & 9 & 8 & 10 & 1 & 17 & 0 & 18 & 18 \\
\hline $\begin{array}{l}\text { MHT negative } \\
\text { C Sensitive }(n=4)\end{array}$ & 0 & 4 & 0 & 4 & 0 & 4 & 0 & 4 & 0 \\
\hline $\begin{array}{l}\text { MHT negative } \\
\text { C Resistant }(n=0)\end{array}$ & 0 & 0 & 0 & 0 & 0 & 0 & 0 & 0 & 0 \\
\hline Total & 10 & 16 & 8 & 18 & 1 & 25 & 0 & 26 & 19 \\
\hline
\end{tabular}

MHT = Modified Hodge Test, $\mathrm{C}=3$ carbapenem drugs tested in the study 


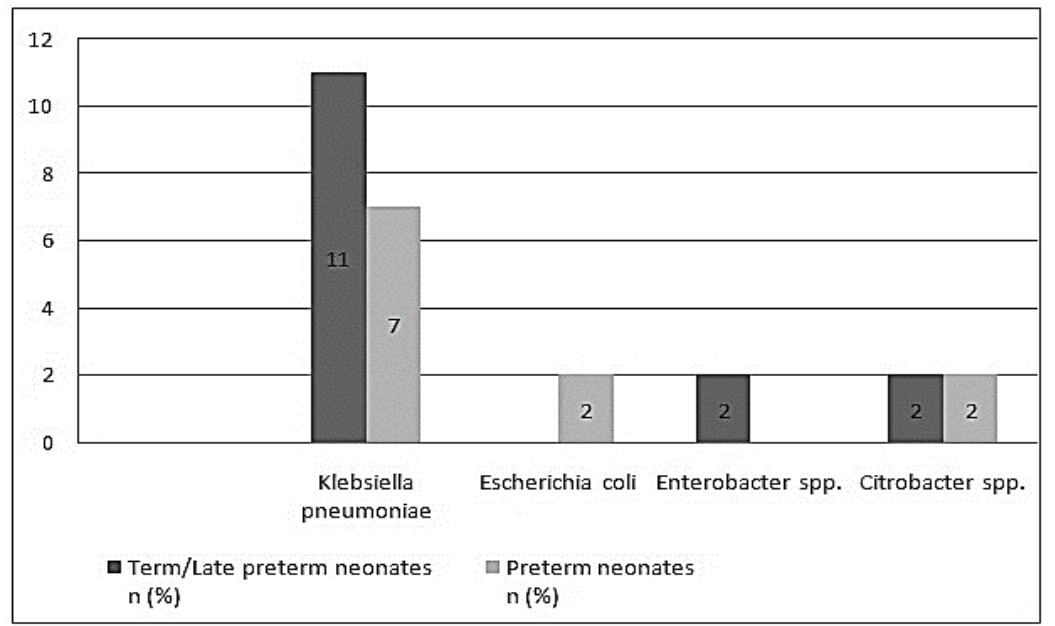

Fig. 1: Possible CRE isolated

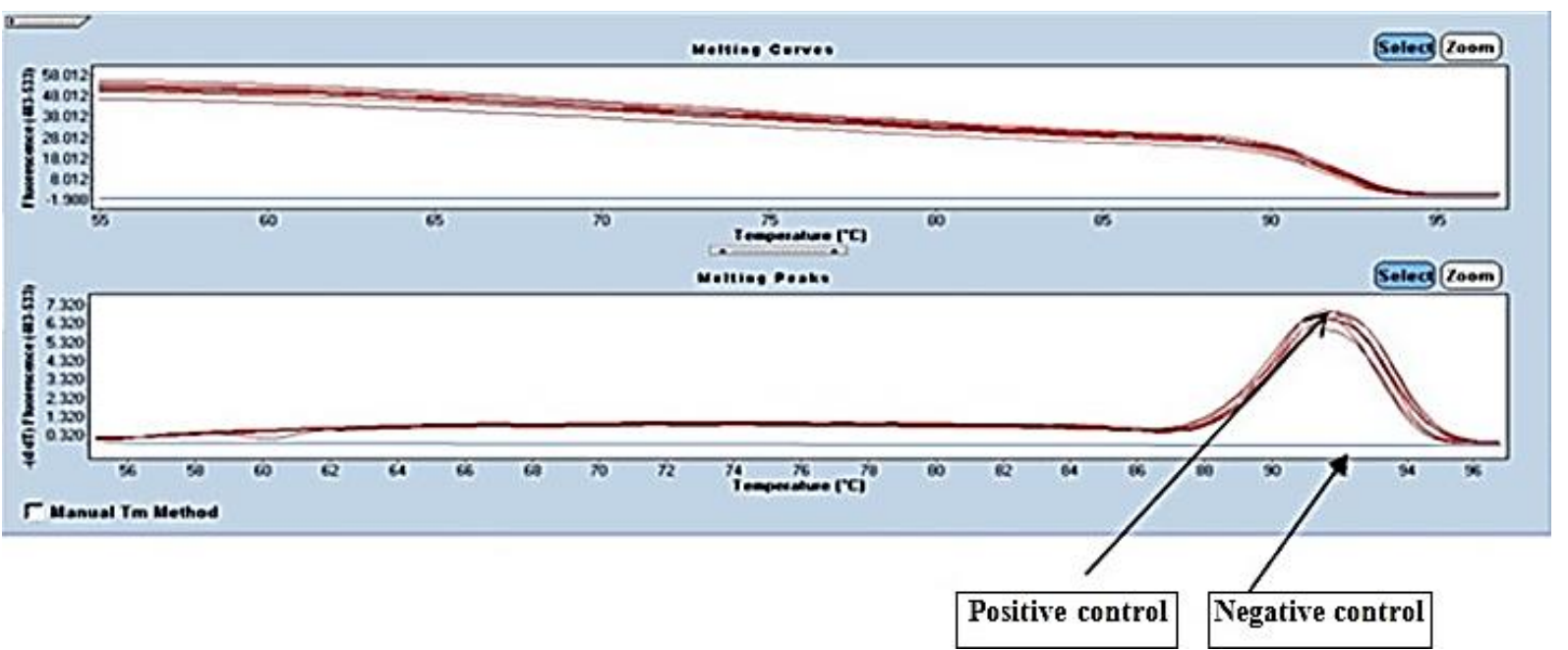

Fig. 2: Demonstrates real-time PCR (Syber green based) amplification and melting curves for blandM-1

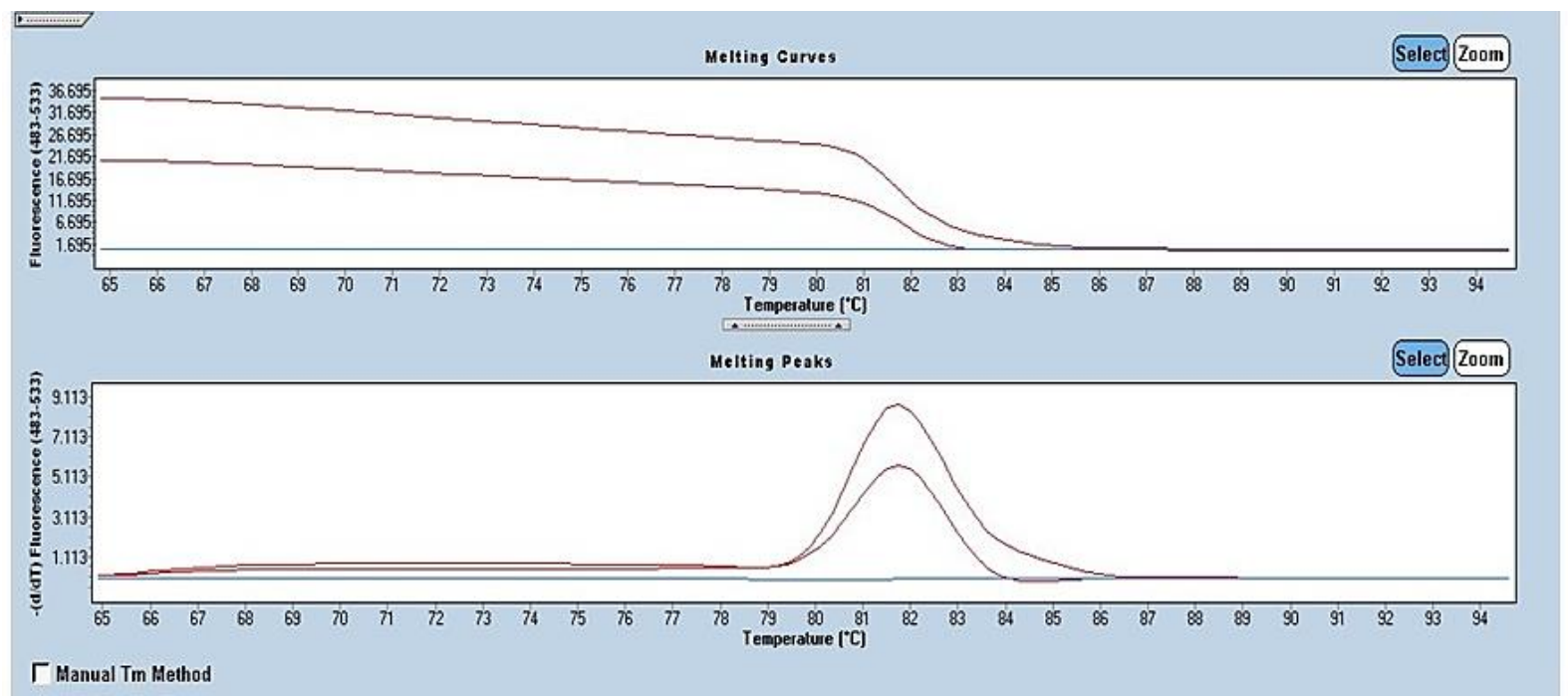

Fig. 3: Demonstrates real-time PCR (Syber green based) amplification and melting curves for bla $a_{\mathrm{IMP}}$ 


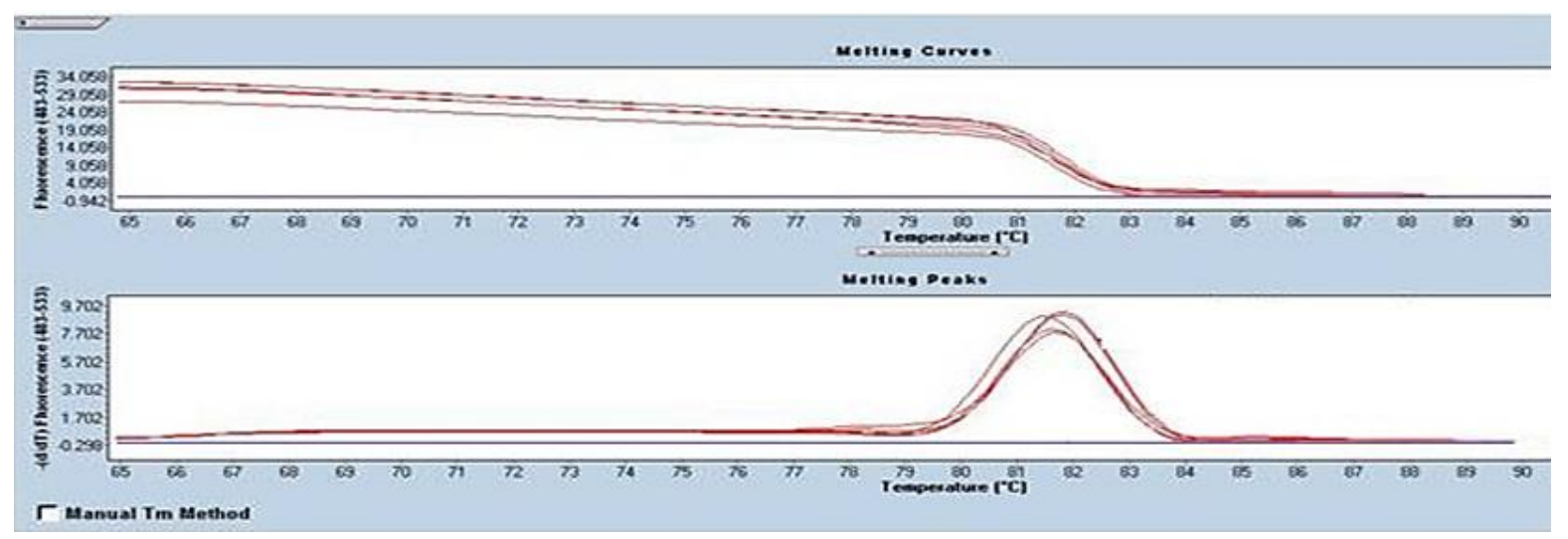

Fig. 4: Demonstrates real-time PCR (Syber green based) amplification and melting curves for blaviM

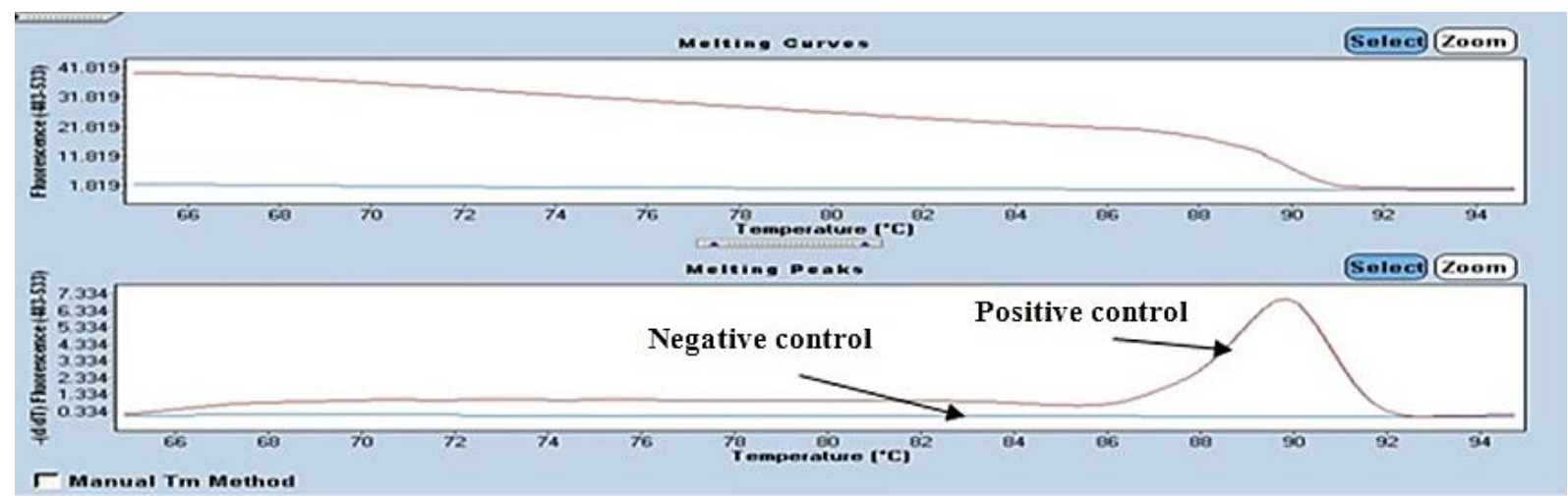

Fig. 5: Demonstrates real-time PCR (Syber green based) amplification and melting curves for bla $\mathrm{KPC}$

\section{Discussion}

Detection of CRE gut colonization among neonates delivered and admitted in NICU being the primary objective of the study was observed in $8.7 \%(26 / 300)$ of the studied population. $10 \%(15 / 150)$ of the term/late preterm neonates and $7.3 \%(11 / 150)$ of the preterm neonates were colonized. Possible CREs were isolated as early as on day 3. Majority of the possible CREs could be isolated by the time the neonates were being discharged (day 4-10). In both the term/late preterm and preterm neonates, Klebsiella pneumoniae $(69.2 \%)$ was the commonest colonizer.

An Indian study showed that the gut colonization with GNB in neonates increased with a longer stay in NICU. ${ }^{15}$ This finding was similar to the present study in terms of increased colonization with duration of hospitalization. Another study conducted in a NICU from Chandigarh showed that $45 \%$ had sterile guts on day 1 and all infants were colonized by day $3 .{ }^{16}$ The focus of the Chandigarh study was only on neonatal gut colonization without reporting AST. While the present study was aimed at CRE gut colonization and no CRE was isolated on day 0 . Neonatal gut colonization with multidrug-resistant Enterobacteriaceae (MRE) in NICU has been documented from UK, Sweden, USA, and India. ${ }^{14}$ However, there is a paucity of data on prevalence of CRE gut colonization in term/late preterm and preterm neonates in these studies.
A study from North India documented E.coli as major gut colonizer followed by Klebsiella pneumoniae and Enterococcus fecalis which is different from the findings of an Indian study from Kolkata that showed the equal prevalence of E.coli and Klebsiella pneumoniae. ${ }^{15,16}$ In a point prevalence survey on CRE transmission among sick children by Roy $\mathrm{S}$ et al. found all 20 CREs were E.coli from 16 body sites including gut of the neonates. ${ }^{6}$ So, it is evident that there might be geographical variation in the gut colonization by the species of Enterobacteriaceae family.

Similar to our study, MDR CRE isolates have been also reported around the world from gut of the adults and neonates. ${ }^{5,6,15,18}$

In a study from Italy by Mosca et al., bla $a_{\mathrm{KPC}}$ was reported in 100\% of the CREs, where carbapenemases production detected by MHT was seen in $84 \%^{15}$ An American study by Raghunathan A et al. showed that PCR assay for the bla $a_{\mathrm{KPC}}$ gene was positive in $82 \%$ of the MHT positive test isolates and was negative in $87 \%$ of MHT negative isolates. ${ }^{19}$

In our study, bla $a_{\mathrm{KPC}}$ gene was not detected in any of the 26 CRE isolates and carbapenemases genes were found in $86.36 \%$ (19/22) MHT positive isolates which include 18 carbapenem-resistant and 1 carbapenem sensitive isolates. The MHT false positivity could be the result of the production of a high level of $\mathrm{AmpC}$ and due to minor carbapenem hydrolysis by CTX-M and AmpC 
enzymes and or presence of other carbapenemases genes with the weak hydrolyzing activity of carbapenemases enzymes. $^{18}$

There are also reports of a difference in carbapenemases genes in different studies around the globe. Logan LK study revealed the presence of NDM, KPC, VIM-1, IMP-4, OXA-181, and SME genes in 64 clinical CRE isolates from the five different countries (India, Israel, Greece, UK, and Spain). Indian CRE isolates of Logan KL study showed the only presence of the $b l a_{\mathrm{NDM}}$ gene. ${ }^{21}$ An Indian study by Roy $\mathrm{S}$ et al. from Kolkata on isolates from NICU with CRE infections focused only on the presence of bla $a_{\mathrm{NDM}-1}$ gene. $^{6}$ Deshpande et al. from Mumbai and Seema et al. from Banaras in their studies also focused on bla $a_{\mathrm{NDM}-1}$ in Enterobacteriaceae from various clinical specimens irrespective of age. ${ }^{22,23}$ This difference of result from our study may be explained by the differences in focus of other studies, the geographical variation in the presence of different carbapenemases genes.

According to $\mathrm{CDC}$ criteria, the prevalence of possible CREs was $8.7 \%$ (26/300) while after final confirmation by PCR, the prevalence of CREs was $6.6 \%$ (19/300) for studied four carbapenemases genes. The difference can be explained by the fact that we have looked for only four types of carbapenemases genes and other mechanisms of carbapenem resistance were also not studied.

In our study, CREs were isolated as early as on day 3. Though most of the CREs were isolated from the sample taken on day 4-10 i.e. before discharge from NICU and no other studies have been conducted to best of our knowledge to find out the CRE gut colonization of hospital delivered and admitted term/late preterm and preterm neonates in NICU. The limitations of the study could be the small number of studied population, no follow up of the persistence of CRE gut colonization in those neonates after discharge from NICU and MICs were not observed in these multidrug-resistant CRE isolates. So, for a better understanding of resistance pattern and mechanisms of gut colonization in neonates, a study should include large sample size with their follow up.

\section{Conclusion}

Neonates in a NICU environment are colonized with potentially pathogenic organisms within the first week of life itself. This colonization may be associated with diseases in the neonatal period (such as sepsis, NEC) as well as post-neonatal diseases (such as atopy, inflammatory bowel disease, irritable bowel syndrome etc). The nosocomial acquisition is the most common cause of CRE colonization. These neonates may carry CREs from the hospital to the community after being discharged. This may increase the likelihood of appearance of CRE infections, new drug resistance patterns and evolution of carbapenemases genes in the community. These CREs have a potential to spread rapidly within the hospital environment, in the community and also across the continents which have become a major public health concern.

\section{References}

1. Delgado-Valverde M, Sojo-Dorado J, Pascual A, Rodríguez-Baño J. Clinical management of infections caused by multidrug-resistant Enterobacteriaceae. Ther Adv Infect Dis. 2013;1:49-69.

2. Kang C, Kim S, Park W, Lee K, Kim H, Kim E, et al. Bloodstream infections caused by antibiotic-resistant gram-negative bacilli: risk factors for mortality and impact of inappropriate initial antimicrobial therapy on outcome. Antimicrob Agents Chemother. 2005;49:76066.

3. Naas T, Nordmann P. Analysis of a carbapenemhydrolyzing class A beta-lactamase from Enterobacter cloacae and of its LysR-type regulatory protein. Proc Natl Acad Sci USA. 1994;91:7693-97.

4. Niranjan DK, Singh NP, Manchanda V, Rai S, Kaur IR. Multiple carbapenem hydrolyzing genes in clinical isolates of Acinetobacter baumannii. Indian J Med Microbiol. 2013;31:237-41.

5. Rai S, Manchanda V, Singh NP, Kaur IR. Zinc-dependent carbapenemases in clinical isolates of family Enterobacteriaceae. Indian J Med Microbiol. 2011;29:275-79.

6. Roy S, Singh AK, Viswanathan R, Nandy RK, Basu S. Transmission of imipenem resistance determinants during the course of an outbreak of NDM-1 Escherichia coli in a sick newborn care unit. J Antimicrob Chemother. 2011;66:2773-80.

7. Rai S, Das D, Niranjan DK, Singh NP, Kaur IR. Carriage prevalence of Carbapenem resistant Enterobacteriaceae in stool samples: A surveillance study. Australas Med J. 2014;7:64-67.

8. United States Centers for Disease Control and Prevention. Laboratory Protocol for Detection of CarbapenemResistant or Carbapenemase-Producing Klebsiella spp. and $E$. coli from Rectal Swabs. Available at: www.cdc.gov/hai/pdfs/labsettings/klebsiella_or_ecoli.pdf (Accessed on 20th January 2017).

9. Crichton PB. Enterobacteriaceae: Escherichia, Klebsiella, Proteus and other genera. In: Mackie \& McCartney Practical Medical Microbiology, $14^{\text {th }}$ ed. Collee JG, Marmion BP, Fraser AG, Simmons A, editors. Elsevier, New Delhi; 2012:361-384.

10. Wayne, USA: Clinical and Laboratory Standards Institute. Performance Standards for Antimicrobial Susceptibility Testing; twenty fourth Informational Supplement 2014; M100 S2. Available at: www.microbiolab-bg.com/wpcontent/uploads/2015/05/CLSI-2014.pdf(Accessed on 20th January 2017).

11. United States Centers for Disease Control and Prevention. Management of Multidrug-Resistant Organisms In Healthcare Settings, 2006. Available at: www.cdc.gov/hicpac/pdf/guidelines/MDROGuideline200 6.pdf (Accessed on 20th January 2017).

12. Manchanda V, Rai S, Gupta S, Rautela RS, Chopra R, Rawat DS et al. Development of TaqMan real-time polymerase chain reaction for the detection of the newly emerging form of carbapenem resistance gene inclinical isolates of Escherichia coli, Klebsiella pneumoniae and Acinetobacter baumannii. Indian J Med Microbiol. 2011;29:249-53. 
13. Mendes RE, Kiyota KA, Monteiro J, Castanheira M, Andrade SS, Gales AC et al. Rapid detection and identification of metallo-beta-lactamase-encoding genes by multiplex real-time PCR assay and melt curve analysis. J Clin Microbiol. 2007;45:544-7.

14. Wang L, Gu H, Lu X. A rapid low-cost real-time PCR for the detection of Klebsiella pneumoniae carbapenemase genes. Ann Clin Microbiol Antimicrob. 2012;11:9.

15. Das P, Singh AK, Pal T, Dasgupta S, Ramamurthy T, Basu S. Colonization of the gut with Gram-negative bacilli, its association with neonatal sepsis and its clinical relevance in a developing country. J Med Microbiol. 2011;60:1651-60.

16. Dutta S, Ganesh M, Ray P, Narang A. Intestinal colonization among very low birth weight infants in first week of life. Indian Pediatr. 2014 Oct;51:807-9.

17. Millar M, Philpott A, Wilks M, Whiley A, Warwick S, Hennessy E, et al. Colonization and persistence of antibiotic-resistant Enterobacteriaceae strains in infants nursed in two neonatal intensive care units in East London, United Kingdom. J Clin Microbiol. 2008;46:560-67.

18. Mosca A, Miragliotta L, Del Prete R, Tzakis G, Dalfino $\mathrm{L}$, Bruno F et al. Rapid and sensitive detection of bla $\mathrm{KPC}_{\mathrm{C}}$ gene in clinical isolates of Klebsiella pneumoniae by a molecular real-time assay. Springerplus. 2013;2:31-35.

19. Raghunathan A, Samuel L, Tibbetts RJ. Evaluation of a Real-Time PCR Assay for the Detection of the Klebsiella pneumoniae Carbapenemase Genes in Microbiological Samples in Comparison With the Modified Hodge Test. Am J Clin Pathol. 2011;135:566-71.

20. Pasteran F, Mendez T, Guerriero L, Rapoport M, Corso A. Sensitive Screening Tests for Suspected Class A
Carbapenemase Production in Species of Enterobacteriaceae. J Clin Microbiol. 2009;47:1631-39.

21. Logan LK. Carbapenem-Resistant Enterobacteriaceae: An emerging problem in Children. Clin Infect Dis. 2012;55:852-59.

22. Seema K, Ranjan Sen M, Upadhyay S, Bhattacharjee A. Dissemination of the New Delhi metallo- $\beta$-lactamase-1 (NDM-1) among Enterobacteriaceae in a tertiary referral hospital in north India. J Antimicrob Chemother. 2011;66:1646-47.

23. Deshpande LM, Rhomberg PR, Sader HS, Jones RN. Emergence of serine carbapenemases (KPC and SME) among clinical strains of Enterobacteriaceae isolated in the United States Medical Centers: report from the MYSTIC Program (1999-2005). Diagn Microbiol Infect Dis. 2006;56:367-72.

How to cite this article: Choudhury DD, Singh NP, Rai S, Batra P, Manchanda V. Carbapenem resistant Enterobacteriaceae neonatal gut colonization: A future concern in healthcare settings. Indian J Microbiol Res. 2018;5(3):348354. 